\title{
El Tratado de Marrakech, ¿libros para ciegos?
}

\section{The Treaty of Marrakech, books for the blind?}

\section{Palabras clave}

Tratado de Marrakech, percepción háptica, imagen táctil.

\section{Keywords}

Treaty of Marrakech, haptic percepcion, tactile image.

\section{Carlos Fuentes Vargas}

$<$ carlos.fuentes.vargas@uacm. edu. $\mathrm{mx}>$

Universidad Autónoma de la Ciudad de México. México

\section{Introducción}

El 30 de abril del 2015 México ratificó el Tratado de Marrakech (SRE, 2015). Este tratado, promovido por la Organización Mundial de la Propiedad Intelectual (OMPI), tiene como objetivo «facilitar el acceso a las obras publicadas a las personas ciegas, con discapacidad visual o con otras dificultades para acceder al texto impreso» (OMPI, 2018). Así, tanto México como los otros veinte países que lo han ratificado, están obligados a implementar excepciones en sus leyes con respecto a los derechos de autor para que se pueda cumplir con los objetivos de la OMPI.

En este contexto, según datos del Instituto Nacional de Estadística y Geografía (INEGI), en México, de los cerca de 120 millones de habitantes, casi 7,2 millones de personas tienen algún tipo de discapacidad (INEGI, 2015) y, de esta población, el 58,4\% corresponde específicamente a la discapacidad visual. Esto significa que hay aproximadamente 4,2 millones de posibles lectores que en principio no tienen a su alcance los textos impresos disponibles en este país. Por supuesto que esta robusta estimación tiene que ser matizada, tan solo hay que considerar que en México de cada 100 personas 55 no leen ningún libro al año (INEGI, 2018).

En este sentido, con el Tratado de Marrakech, las personas ciegas tendrían la oportunidad de acceder a un conocimiento del que hasta ahora han sido

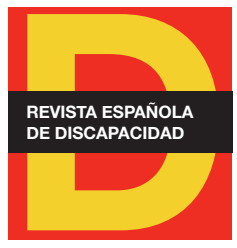

Para citar:

Fuentes, C. (2019): "El Tratado de Marrakech, ¿libros para ciegos?". Revista Española de Discapacidad, 7 (I): 251-255.

Doi: <https://doi.org/10.5569/23405104.07.01.13>

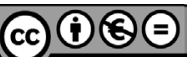


excluidas. No obstante, este mismo tratado invita a la reflexión sobre la relación que existe entre los contenidos de las obras publicadas, cualquiera que estos sean, y las personas con discapacidad visual. Es decir, cabe preguntarnos si los autores al momento de concebir su obra consideraron al posible lector como una persona ciega. No sería desmedido considerar que no lo hicieron.

Es evidente que en la gran diversidad de títulos hasta ahora publicados, existen diferencias abismales para su comprensión en las personas con discapacidad visual. Por ejemplo, el contenido de un libro de poesía prácticamente puede transcribirse en código braille en su totalidad, pero con esta acción, incluso en un texto de esta naturaleza, podría ser alterado el sentido de la obra si consideramos que se necesita aproximadamente cuatro veces más espacio para escribir en braille lo que se escribe en tinta a 11 puntos, por lo que la estructura de las estrofas puede quedar seriamente comprometida. Por ello, el cuidado en la transcripción no sólo es en texto sino también en la forma. En el otro extremo, sin embargo, un típico libro de matemáticas está confeccionado con gráficos que no solo ilustran un concepto, sino que son inherentes a un código matemático que al unísono son parte de la construcción del concepto en cuestión. La combinación de los lenguajes utilizados en este último (gráficos, código matemático y lenguaje verbal) exacerban la complejidad en el intento de transcribirlo para que sea accesible a personas con esta discapacidad. El resultado de este esfuerzo, en el mejor de los casos, es un texto que podrá ser legible, pero distando de ser comprensible.

Así, entre los casos extremos citados, el universo de contenidos que los autores tienen la necesidad de alternar con imágenes es vasto. Esta necesidad puede ser motivada porque los seres humanos están condicionados a conectarse con el mundo a través de imágenes (Correa, 2014). Se puede decir que una imagen es una representación inundada de marcos de referencia que, para Millar (1994), se construyen a través de distintas modalidades sensoriales. Dada la importancia en este ámbito, se han escrito trabajos enfocados específicamente a la construcción de una teoría sobre la imagen, como los textos de Villafañe y Mínguez (2002) y Acaso (2006), por citar algunos.

Asimismo, en el desarrollo de las personas con discapacidad visual, los marcos de referencia y la construcción de la imagen ocupan un lugar imperativo. Si la imagen se presenta táctilmente para ellos, ésta puede representar una realidad capturada de modelos que se transforma en un signo icónico (Correa, 2014). En este sentido, Millar (1994) propone que son dos capacidades diferentes las que permiten por un lado identificar la forma y, por otro, localizar dicha forma espacialmente. Dado que la ceguera reduce la información sobre los marcos de referencia externos, es necesario proporcionarles esta información utilizando el movimiento (Millar, 1994).

Las consideraciones expuestas conllevan a diversos autores a reconocer que la hechura de las imágenes para personas con discapacidad visual debe estar provista de elementos específicos que tienen su base en los referentes innatos a la falta de visión. Bardisa (1992) expone ampliamente los procesos hápticos de la percepción y el tacto, y cómo estos intervienen en la construcción del dibujo en las diferentes etapas de los niños ciegos. Finalmente, cabe mencionar los trabajos de Rosa y Ochaita (1998) que, en el marco de la psicología de la ceguera, hacen énfasis en las diferencias entre la percepción visual y háptica, siendo una de ellas la acción para recopilar información a través del sistema háptico, que se lleva a cabo de manera lenta y secuencialmente. 


\section{La adaptación de libros en el marco del Tratado de Marrakech}

Esta sucinta exposición de sólo algunos trabajos encaminados a explicar, entre otras, las diferencias de la percepción entre personas ciegas y normovisuales, son evidencias que advierten de que las imágenes, y en específico las empleadas en textos impresos, son germinadas a partir de los referentes sensoriales para quien está dirigida la obra. Si bien con la tecnología actual una imagen en tinta es factible transformarla íntegramente a táctil, pretender sin embargo con este proceso transmitir la misma intención de información indistintamente a personas ciegas o normovisuales, atendiendo a los autores acabados de citar, puede ser infructuoso. Así, en el marco del Tratado de Marrakech, es razonable la pregunta ¿cómo transcribir?

En este esfuerzo por acercar el texto impreso a personas ciegas se corre el riesgo de quedar confinados en un cúmulo de buenas intenciones propiciado por la trascendencia de esta tarea. Por ejemplo, situaciones de esta naturaleza se pueden identificar en los libros de instrucción básica que distribuye gratuitamente la Secretaría de Educación Pública (SEP). La SEP también distribuye estos libros con su respectiva transcripción a código braille, como una respuesta a la inclusión y al reconocimiento del derecho inalienable a la educación, ambos ratificados en la Convención sobre los Derechos de las Personas con Discapacidad (Naciones Unidas, 2006).

Para ilustrar lo anterior, la figura 1 muestra dos páginas que corresponden a una misma lección del libro de español para segundo año de primaria del ciclo escolar 2017-1018 (SEP, 2018). La página que se muestra en el lado izquierdo corresponde a la lección para niños normovisuales y en el lado derecho la transcripción en braille. La versión en tinta está compuesta principalmente por imágenes, las cuales son por sí mismas la esencia de la estrategia para alcanzar el propósito de esta lección. En la versión para niños ciegos se intercambiaron las imágenes por los nombres de los objetos ilustrados, justo el cometido a realizar, lo que evidencia inconsistencias para lograr los mismos objetivos.

Figura 1. Imágenes en tinta y braille de una lección del libro de español para segundo año de primaria para el ciclo escolar 2017-1018
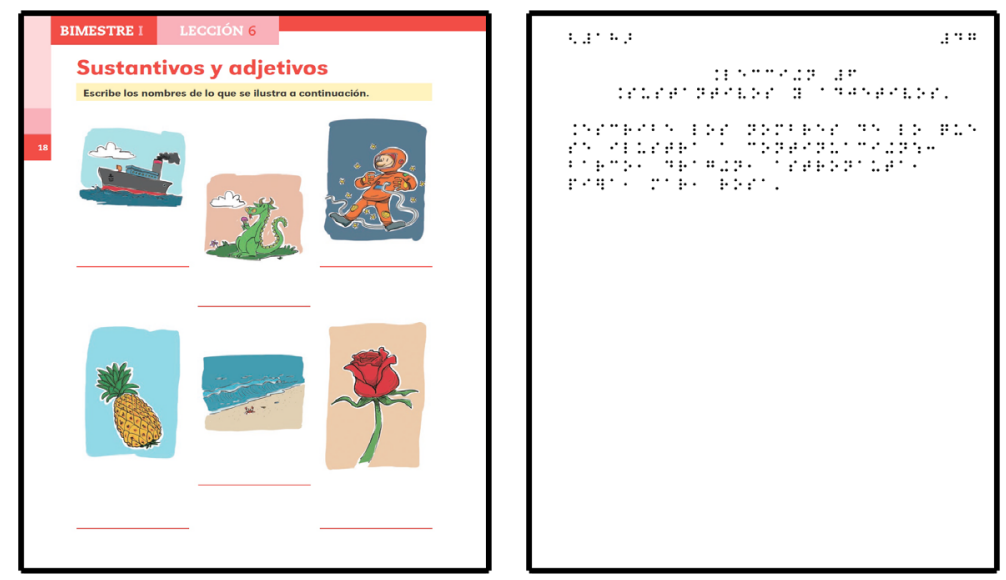

Fuente: SEP (2018). 
Luego, ¿implican estas inconsistencias la necesidad de transcribir también las imágenes? Si nos ceñimos al Tratado de Marrakech quizá la respuesta inmediata es que sí. Sin embargo, reiterando los estudios con respecto a la construcción de imágenes desde marcos referenciales diferentes, con esta acción no se garantiza alcanzar los mismos objetivos de la versión en tinta. Entonces, lo conducente es proponer una lección desde el contexto de la falta de visión que derive en alcanzar los mismos objetivos. La igualdad implicaría transcribir íntegramente para que todos tengan el mismo libro, pero la equidad implicaría dar el libro con las modificaciones pertinentes para alcanzar las mismas metas.

No es nada desdeñable el esfuerzo de la SEP por proveer libros en braille a los niños ciegos ahora integrados en aulas con niños normovisuales. Al contrario, es una respuesta institucional para atender la no discriminación. Es sabido, al menos en el caso de México, que la población con edades entre 3 y 29 años con discapacidad visual que asiste a la escuela es del $42,4 \%$, mientras que en el caso de las personas sin discapacidad es del 60,5\% (INEGI, 2015). Lo que sí refleja esta situación es la carencia de textos escritos considerando que el lector es una persona ciega. Realizarlos implicaría que el autor toma conciencia de los referentes sensoriales, herramientas cognitivas y recursos técnicos existentes para que el contenido no sólo sea legible sino comprensible.

\section{Conclusiones}

A manera de conclusión de esta reflexión, se pueden identificar dos caminos paralelos que conlleven a cumplir las intenciones de acercar el texto impreso a personas ciegas. Un camino es transcribir íntegramente a braille los textos incluyendo las imágenes, con lo que sin duda se cumplirá un derecho de las personas ciegas, pero transcribir recurriendo a las modificaciones pertinentes, aunque implique la modificación de cierto contenido original, impactará en un mejor reconocimiento de la intención del autor. El otro camino es impulsar la creación de obras con la consigna de que su principal lector es una persona ciega. Para ello, es imprescindible considerar las herramientas cognitivas que las personas ciegas utilizan como recurso para apropiarse de conocimiento nuevo.

En este amplio espectro de oportunidades que ahora emerge, los textos ubicados en el área educativa dirigida a lectores niños es primordial. Es este área un termómetro que refleja el rezago en diferentes ámbitos en que se encuentran las personas con discapacidad visual con respecto a las personas normovisuales. Aunado a esto, también se debe explotar el sentido háptico en los textos, sentido que puede detonar procesos de aprendizaje por el vasto universo de posibilidades que a través de los gráficos se pueden crear. El Tratado de Marrakech por supuesto que brinda una oportunidad de seguir construyendo mejores condiciones para las personas con discapacidad, pero no se logrará sólo por la modificación en las leyes, sino por la oportunidad de nutrirlo con la ya generosa cantidad de experiencias por parte de personas que han dedicado años de trabajo en este rubro. 


\section{Referencias bibliográficas}

Acaso, M. (2006): El lenguaje visual. Barcelona: Paidós.

Bardisa, L. (1992): Cómo enseñar a los niños ciegos a dibujar. Madrid: ONCE.

Correa, P. (2014): "Toward a construction and a reading model of tactile graphics for educational purposes". Terra Haptica, 4: 23-32.

INEGI (2018): Módulo sobre Lectura (en línea). <https://www.inegi.org.mx/contenidos/programas/molec/doc/resultados_molec_feb18.pdf>, acceso 19 de octubre de 2018.

INEGI (2015): Estadísticas a propósito del Día Internacional de las Personas con Discapacidad (3 de diciembre) (en línea). <https://www.inegi.org.mx/contenidos/saladeprensa/aproposito/2015/discapacidad0.pdf>, acceso 7 de septiembre de 2018.

Millar, S. (1994): Understanding and representing space. Theory and evidence from studies with blind and sighted children. Oxford: Oxford University Press.

Naciones Unidas (2006): Convención sobre los Derechos de las Personas con Discapacidad. Nueva York: ONU (en línea). <http://www.un.org/spanish/disabilities/default.asp?id=497>, acceso 18 de septiembre de 2018.

OMPI (2018): Tratado de Marrakech para facilitar el acceso a las obras publicadas a las personas ciegas, con discapacidad visual o con otras dificultades para acceder al texto impreso (en línea). <http://www.wipo.int/treaties/ es/text.jsp?file_id=302979>, acceso 10 de octubre de 2018.

Rosa, A. y Ochaita, E. (1988): "Estado actual de la investigación en psicología de la ceguera". Infancia y Aprendizaje, 41: 53-62.

SEP (2018): Sustantivos y adjetivos (en línea). <https://cdn.cicloescolar.mx/libros/2018/primaria/segundo/espanol_alumno/espanol_segundo_p18.png>, acceso 5 de octubre de 2018.

SRE (2015): La Política de Derechos Humanos de México (en línea). <https://embamex.sre.gob.mx/reinounido/ images/stories/reinounido/DerechosHumanos/2015/Esp/sn9.pdf>, acceso 19 de octubre de 2018.

Villafañe, J. y Mínguez, N. (2002): Principios de la teoría general de la imagen. Madrid: Pirámide. 